\title{
Kinetic Study on the Deoxidation of Steel ${ }^{*}$ -Precipitating Deoxidation by Silicon and Manganese-
}

\author{
By Nobuo Sano,** Sumio Shiomi,** and Yukio Matsushita**
}

\section{Synopsis}

Deoxidation problems of nonmetallic inclusions being formed as reaction products were dealt with from the kinetic viewpoint on the example of silicon and/or manganese deoxidation.

The experimental results are as follows:

(1) Silica particles deoxidation products of silicon addition, are very hard to separate from molten iron because of their poor ability to coalesce.

(2) Manganese oxide particles in case of much manganese addition consist of two phases which suggest that liquid and solid phases get together without any difficulty. Thus they grow to rather large particles and are separated in a short time.

(3) Even in complex deoxidation of silicon and manganese where solid silica particles are expected to be produced according to equilibrium theory, large and globular particles of iron and manganese silicate were observed.

(4) The property of liquid silicate particle to coalesce and be easily separated from molten steel is confirmed.

(5) The motion of iron bath by induction stirring increased the growth rale of all kinds of deoxidation products and proved effective for their removal from molten iron.

(6) Crucible materials influenced not only on the deoxidation but on the reoxidation behaviour as a result of reactions at the metal-crucible interface.

(7) The experiment under oxidizing atmosphere showed that the rate of reoxidation was very large and in contradiction to the above-mentioned the addition of only silicon gave desirable results, because a viscous film formed prevented the penetration of oxygen into iron bath from atmosphere or slag.

The nucleus size and nucleation rate were calculated and the latter proved so large that this step could not be a rate-determining one of deoxidation. The following supposed mechanisms of the growth of deoxidation products uere applied to the discussions of the experimental results. There are:

(1) coalescence by Brosenian movement

(2) growth by diffusion of oxygen or deoxidizer atom to the surface of particle

(3) coalescence during floating up.

Finally the maximum particle size to be observed under experimental conditions was calculated; it was in good agreement with measured one.

These experimental results were applied to the explanation of those obtained in the industrial open hearth deoxidation.

\section{Introduction}

The formation mechanism of deoxidation products was investigated by studying the effects of a number of factors, (e.g. bath motion, atmosphere, crucible materials, and methods for the addition of deoxidizers), on the rate of deoxidation. A decision was made to study the deoxidation kinetics of silicon and manganese in view of the fact that the equilibrium reactions between oxygen and the elements in liquid iron have been investigated in some detail during the past few years.

\section{Experimental Method}

1 to $1.5 \mathrm{~kg}$ of molten iron initially saturated with oxygen, was deoxidized with silicon and/or manganese. After various time intervals, suction samples of 5 to $10 \mathrm{~g}$ were drawn from the bath with a silica tube and rapidly quenched to room temperature. The samples were analysed by conventional chemical methods for manganese, silicon, and oxygen.

Two different furnaces were used to study the effect of bath motion; a high frequency induction furnace $(15 \mathrm{~kW}, 26 \mathrm{kc})$, and a spiral graphite resistance furnace (Fig. 1) in which the motion of the bath was reduced to a minimum.

Temperatures were measured by dipping a Pt$6 \% \mathrm{Rh} / \mathrm{Pt}-30 \% \mathrm{Rh}$ thermocouple into the melt and controlled to within $\pm 10^{\circ} \mathrm{C}$ of the desired value by

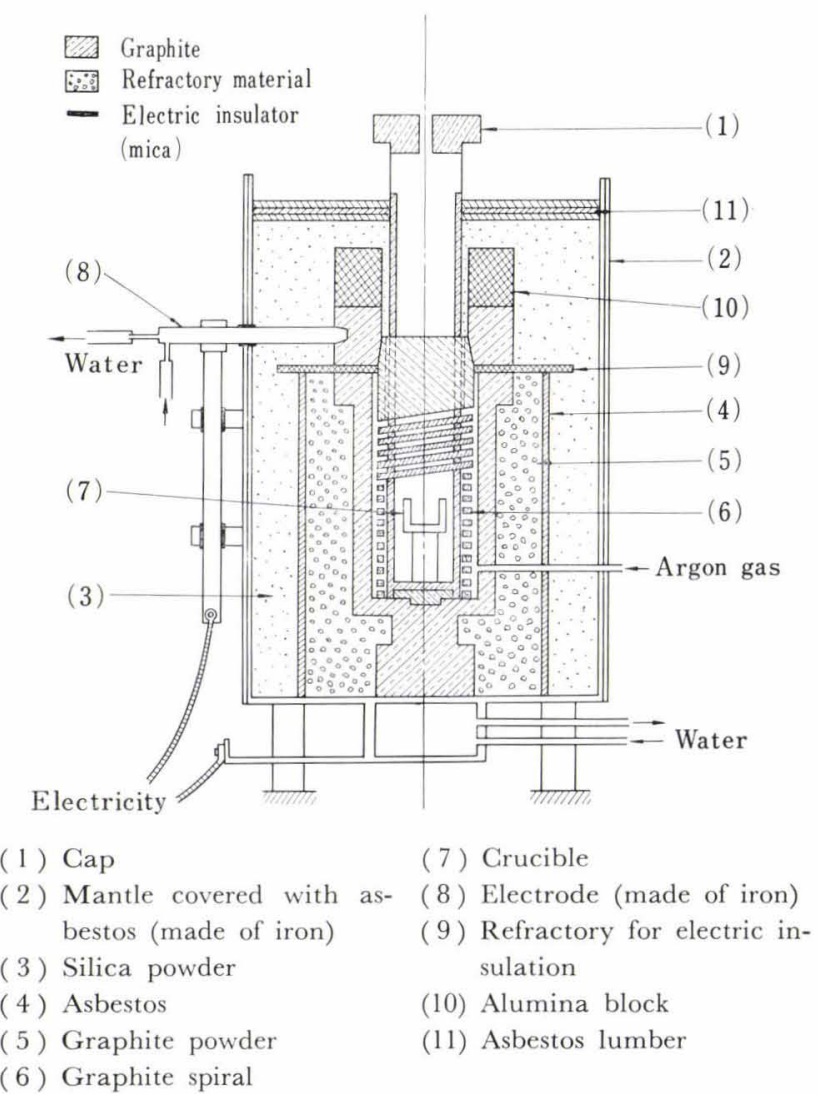

Fig. 1. Graphite spiral resistance furnace (scale 1:10)

* Presented at the 61st ISIJ Meeting, April, 1961 in Tokyo, the 62nd, October, 1961 in Akita, the 64th, October, 1962 in Hiroshima, and the 65th, April, 1963 in Tokyo. Originally published in Tetsu-to-Hagané, 51 (1965), 19 in Japanese. This paper is partially abstracted from the thesis presented by N. Sano for the doctorate degree in Department of Metallurgy, the University of Tokyo, in March, 1964.

** The University of Tokyo, Hongo, Bunkyo-ku, Tokyo. 
adjusting the power input to the furnace. Magnesia, silica, lime, and alumina crucibles were fabricated in the laboratory from the first grade chemical reagents or refractory sand, supplied by Norton Refractories.

\section{Results and Discussion}

\section{Deoxidation of Unstirred Melt}

Experiments were carried out under an argon atmosphere in order to simulate the conditions which exist during ladle deoxidation when oxidation by air and movement within the melt are comparatively slight.

\section{Deoxidation by Silicon}

Figs. 2 and 3 show the results of deoxidation by $0.4 \%$ silicon of a melt containing initially $0.07 \%$ oxygen. The oxygen content decreased rapidly during the first minute and after that, at a much slower rate. After $16 \min K^{\prime}{ }_{\mathrm{Si}}\left(=\underline{\mathrm{Si}} \cdot \underline{\mathrm{O}}^{2}\right)$ was still three times greater than the equilibrium constant for the silicon deoxidation. Silica particles attained their maximum size $(40 \mu)$ about $1 \mathrm{~min}$ after the addition of the silicon (Photo. 1). With increasing time, the particles de-

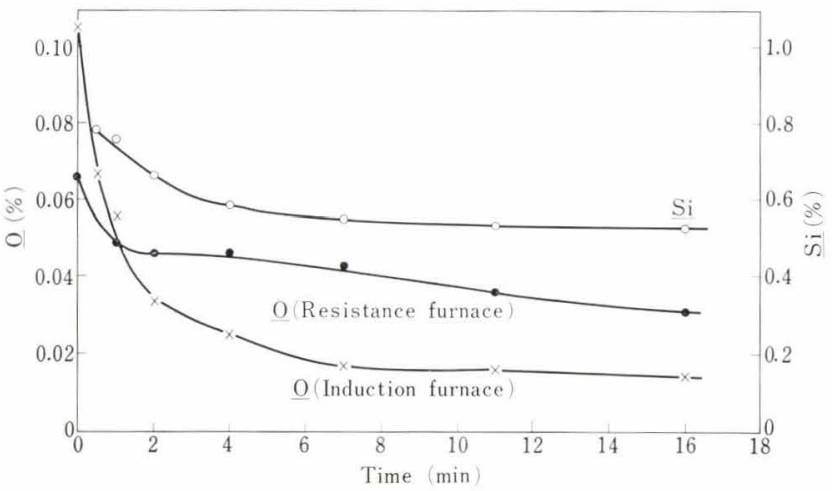

Fig. 2. Run of deoxidation after the addition of $0.4 \%$ silicon

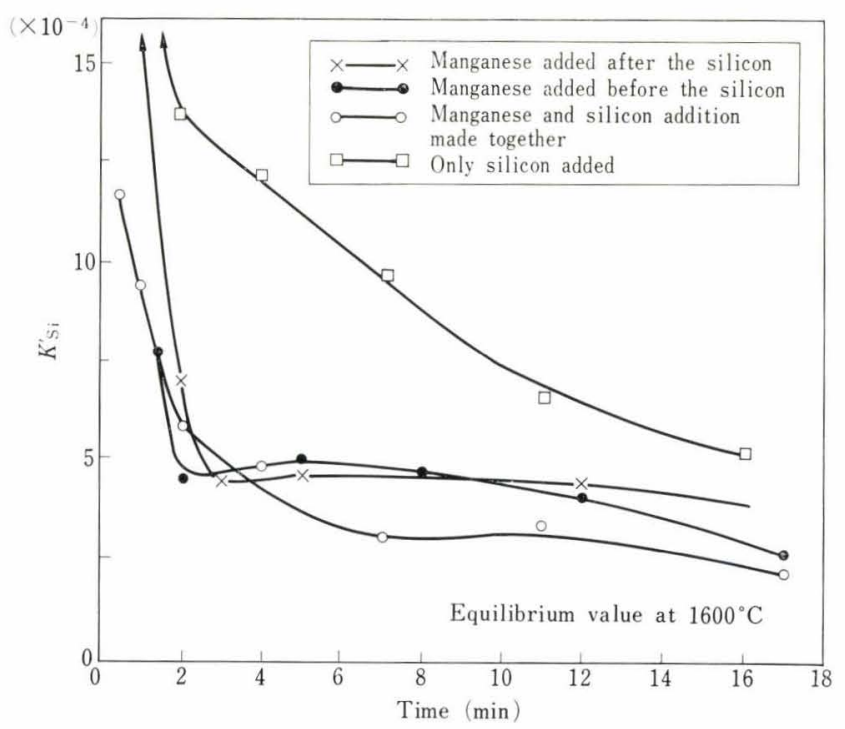

Fig. 3. $K^{\prime} \mathrm{Si}$ value change after the addition of $0.4 \%$ manganese and $0.4 \%$ silicon creased in size, but even after $16 \mathrm{~min}$, silica particles $(6-8 \mu)$ were still observable (Photo. $1(b))$. These facts suggest that it is very difficult for silica to separate out from an iron melt.

\section{Deoxidation by Manganese}

Fig. 4 shows the results of deoxidation by $0.8 \%$ manganese. The rate of deoxidation was almost the same in both stirred and unstirred melts. The products of deoxidation consisted of angular or rodlike particles of $\mathrm{MnO}(30 \mu)$ and large spherical particles $\mathrm{MnO}-\mathrm{FeO}$ solid solution which appeared to be formed by coalescence (Photo. 2). The size and number of particles decreased with time and after $16 \mathrm{~min}$ no more particles could be detected. It is because of the fact that the deoxidation products coalesce and

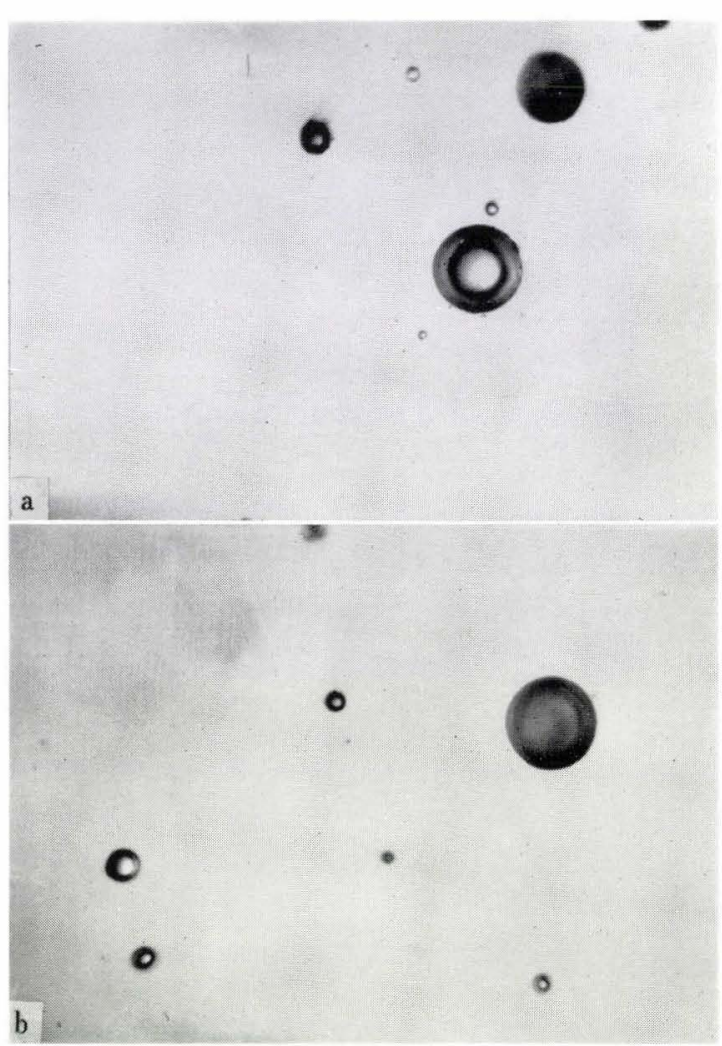

Photo. 1. Deoxidation products after addition of $0.4 \%$ silicon (unstirred bath)

(a) $(\times 500) 30 \mathrm{sec}$

(b) $(\times 500) 2 \mathrm{~min}$

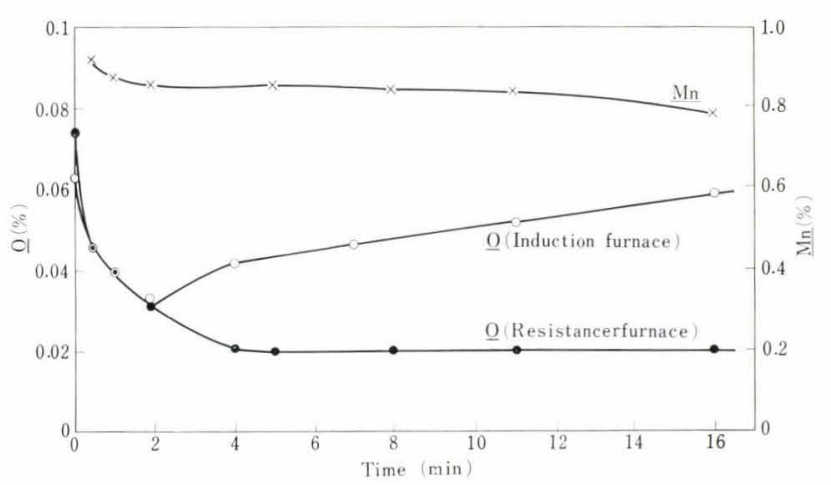

Fig. 4. Run of deoxidation after the addition of $0.8 \%$ manganese 
separate readily from molten iron, that manganese is considered a good deoxidizer.

\section{Deoxidation by Manganese and Silicon}

i. $0.4 \% \mathrm{Si}, 0.4 \% \mathrm{Mn}$

According to the equilibrium data, the deoxidation product should be solid silica. Fig. 5 shows the results obtained when mixtures of silicon and manganese were added to the melt. There was an improvement in deoxidation with both manganese and silicon present rather than silicon alone. When manganese was added $1 \mathrm{~min}$ after the silicon, the deoxidation rate did not change but when silicon was added after manganese, the deoxidation rate was increased because the rim of the angular $\mathrm{MnO}$ particles was reduced with the addition of silicon to give almost spherical liquid silicates (Photo. 3).

ii. $0.2 \% \mathrm{Si}, 0.8 \% \mathrm{Mn}$

A consideration of thermodynamic data indicates that under these conditions, a liquid silicate should be formed. From the plot of $K^{\prime}\left(=\underline{\mathrm{Si}} \cdot \underline{\mathrm{O}}^{2}\right)$ vs. time, a value of 0.4 is obtained for the activity of silica and this implies the formation of liquid silicate. ${ }^{1)}$ The deoxidation rate was almost the same regardless of the order of deoxidizer addition. Spherical silicate particles $(80-200 \mu)$ were observed during the first minute of deoxidation.

The results outlined above are discussed on the basis of several models which have been proposed for the formation of oxides. Throughout this study it was assumed that the rate of solution of the deoxidizers was sufficiently fast not to be rate determining. To simpli-

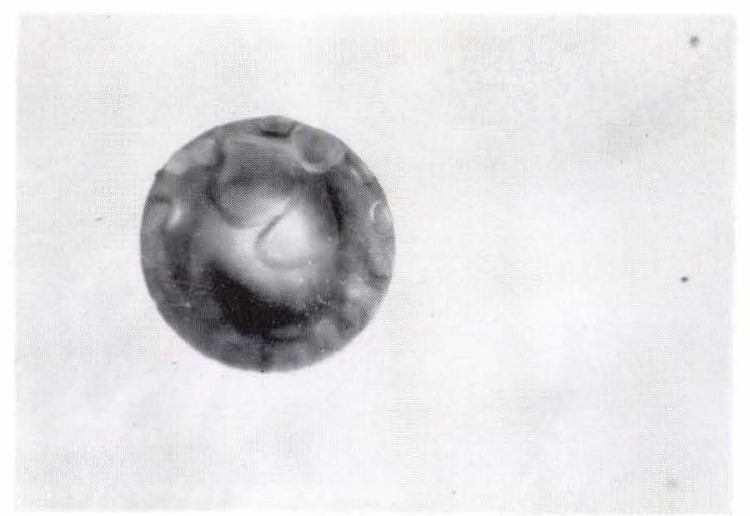

Photo. 2. Deoxidation products after addition of $0.8 \%$ manganese (unstirred bath) $(\times 500) 30 \mathrm{sec}$

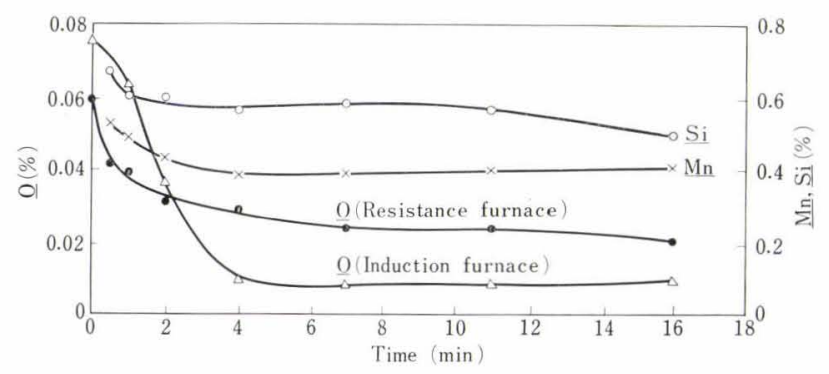

Fig. 5. Run of deoxidation after the addition of $0.4 \%$ manganese and $0.4 \%$ silicon fy the discussion, the material is treated in two subsections: (a) Nucleation and (b) Growth and Floatation.

\section{(a) Nucleation}

The radius of the nucleus $r^{*}$ and nucleation rate $I$ can be calculated from the following equations:2)-4)

$$
\begin{gathered}
r^{*}=\frac{2 \sigma M}{\rho R T \ln \left(C / C_{s}\right)} \\
I=A \cdot \exp \left(-\Delta G^{*} / k T\right)
\end{gathered}
$$

where,

$$
\begin{gathered}
A=n^{\prime}\left(\begin{array}{c}
\sigma \\
k T
\end{array}\right)^{1 / 2}\left(\frac{2 V}{9 \pi}\right)^{1 / 3} n \frac{k T}{h} \\
\Delta G^{*}=\begin{array}{c}
4 \pi r * 2 \\
3
\end{array} \quad \ldots \ldots . . .
\end{gathered}
$$

$\sigma$ : interfacial tension between liquid iron and oxide

$\rho$ : density of oxide

$M$ : molecular weight of oxide

$T$ : absolute temperature

$C / C_{s}$ : degree of supersaturation

$n^{\prime}$ : number of atoms on the surface of the nucleus

$n$ : number of atoms in $1 \mathrm{~cm}^{3}$ of liquid iron

$h$ : Planck's constant

\lrcorner $G^{*}$ : activation energy for nucleation.

Table 1 shows the calculation where Popeli's ${ }^{4)}$ data are partially cited. According to this calculation, nucleation should occur immediately after the de-

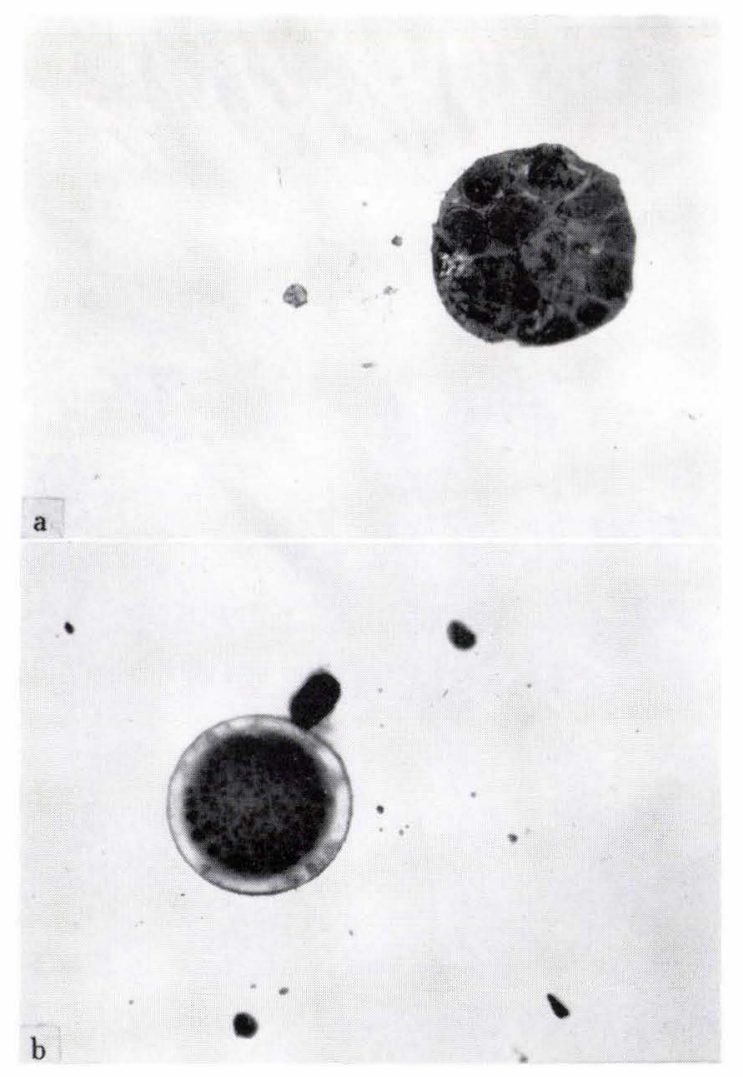

Photo. 3. Deoxidation products in the case of $0.4 \%$ manganese added before $0.4 \%$ silicon (unstirred bath)

(a) $(\times 200) 1 \mathrm{~min}$

(b) $(x 200) 2 \mathrm{~min}$ 
Table 1. Calculated nucleus sizes and nucleation rates

\begin{tabular}{|c|c|c|c|c|c|c|c|}
\hline \multirow{2}{*}{ Species } & \multirow{2}{*}{$\begin{array}{c}\text { Interfacial } \\
\text { energy } \\
\sigma\end{array}$} & \multirow{2}{*}{$\begin{array}{l}\text { Nucleus size } \\
\text { and nucleation } \\
\text { rate }\end{array}$} & \multicolumn{5}{|c|}{$C / C_{s}$ supersaturation degree } \\
\hline & & & 1.5 & 3 & 5 & 10 & 100 \\
\hline $\mathrm{SiO}_{2}$ & 420 & $\gamma_{I}^{*}$ & $\begin{array}{l}59 \\
10^{-760}\end{array}$ & $\begin{array}{l}22 \\
10^{-102}\end{array}$ & $\stackrel{16}{3 \cdot 10^{-37}}$ & $\stackrel{11}{2 \cdot 10^{2}}$ & $\begin{array}{r}7.4 \\
10^{21}\end{array}$ \\
\hline $\mathrm{MnO}$ & 620 & $r_{I}^{*}$ & $\begin{array}{l}24 \\
5 \cdot 10^{-196}\end{array}$ & $\begin{array}{l}9.1 \\
50\end{array}$ & $\begin{array}{l}6.1 \\
7 \cdot 10^{20}\end{array}$ & $\begin{array}{l}4.6 \\
2 \cdot 10^{27}\end{array}$ & $\begin{array}{l}3.1 \\
3 \cdot 10^{32}\end{array}$ \\
\hline $\mathrm{FeO}-\mathrm{MnO}-\mathrm{SiO}_{2}$ & 700 & $\gamma_{I}^{*}$ & $\begin{array}{l}42 \\
10^{-820}\end{array}$ & $\stackrel{16}{3 \cdot 10^{-79}}$ & $\begin{array}{l}71 \\
2 \cdot 10^{-16}\end{array}$ & $\begin{array}{l}7.5 \\
2 \cdot 10^{10}\end{array}$ & $\begin{array}{l}5.0 \\
2 \cdot 10^{25}\end{array}$ \\
\hline
\end{tabular}

$\gamma^{*}$ in $\AA, I$ in nuclei $/ \mathrm{cm}^{3} \mathrm{sec}, \sigma$ in $\mathrm{erg} / \mathrm{cm}^{2}$.

oxidizer dissolves since in this work the values of $C / C_{s}$ for silicon, manganese, and silicon-manganese deoxidation were 100,5 , and 100 , respectively.

Using Bogdandy's equation for fume formation, ${ }^{5)}$ the time for nucleation, $t_{k}$, for the formation of silica was calculated to be $1.9 \times 10^{-6} \mathrm{sec}$, which again implies very rapid nucleation.

(b) Growth Mechanism

(i) Coalescence by Brownian Movement

Smoluchowski's theory ${ }^{6}$ for the coalescence of colloidal particles was applied to the coalescence and growth of oxide particles, with two assumptions:

(1) particles are too small to float out of the melt,

(2) initially there are $\nu_{0}$ nuclei of uniform size in the melt giving a concentration of $C_{o} / \mathrm{cm}^{3}$.

Suppose two particles coalesce by Brownian movement when the distance between them is $\sigma$. The number of particles joined $\nu_{k}$, by $k$ original particles (nuclei) at time $t$ is:

$$
\nu_{k}=\nu_{0} \frac{\left(\alpha \nu_{0} t\right)^{k-1}}{\left(1+\alpha \nu_{0} t\right)^{k+1}}
$$

where,

$$
\begin{aligned}
\nu_{0} & =C_{0} V=I_{0} t_{k} V\left(=1.9 \times 10^{5} / \mathrm{cm}^{3}\right) \\
\alpha & =4 \pi D \sigma \\
D & =\frac{k T}{6 \pi \mu r}
\end{aligned}
$$

\section{$I_{0}:$ nucleation rate}

$t_{k}:$ nucleation time

$V$ : volume of liquid iron

$D$ : diffusivity

$\mu$ : viscosity of liquid iron.

Particles of this size are observed most at

$$
t_{\max }=\frac{k-1}{2 \alpha \nu_{0}}
$$

derived by differentiating Eq. (5).

By the mass balance

$$
k \frac{4 \pi r^{* 3}}{3}=\frac{4 \pi}{3} r^{3}
$$

and then,$$
r^{3}=k r^{* 3}=\left(2 \alpha \nu_{0} t_{\max }+1\right) r^{* 3}=3 b t+r * 3
$$$$
\text { where, } r \text { : radius of grown particle }
$$$$
b: \text { constant. }
$$

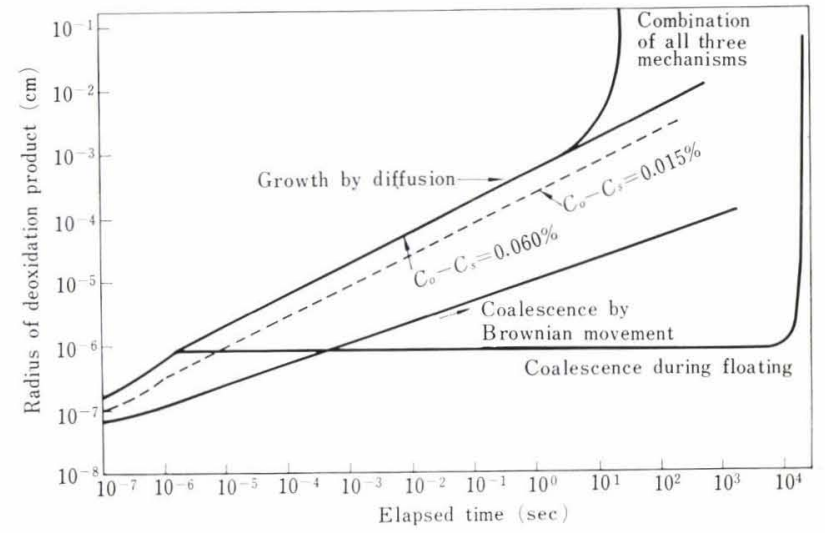

Fig. 6. Relations between the radius of deoxidation products and the elapsed time after the addition of deoxidizers based on some supposed mechanisms. This figure is concerned with the growth of silica.

Assuming $\sigma=3 r$ and $t=t_{\max }$, the relationship between the radius of particle $r$ and time $t$ is calculated for $\mathrm{SiO}_{2}$ as follows:

$$
r \fallingdotseq 10^{-5} \times t^{1 / 3}+7.5 \times 10^{-8}
$$

where $r^{*}$ (for $\left.\mathrm{SiO}_{2}\right)=7.5 \times 10^{-8} \mathrm{~cm}$ is substituted.

This equation is plotted in Fig. 6. At $100 \mathrm{sec}$ this equation predicts a particle size of $0.5 \mu$, which is significantly different from the size of the particles, actually observed $30 \mu$.

(ii) Growth by Diffusion

Assuming that a spherical particle grows by the steady state diffusion of oxygen or deoxidizer element, ${ }^{7)}$ Eq. (10) is derived.

$$
r^{2}=r^{* 2}+\frac{2 D\left(C_{o}-C_{s}\right) \rho_{M} M_{s}}{100 \rho_{s} M_{M}} r^{* 2}+2 a t
$$

where, $M:$ molecular weight

$\rho$ : density (Suffix $s$ and $M$ refer to oxide and metal, respectively.)

$C_{0}$ : initial concentration of deoxidizer in metal

$C_{s}$ : concentration in equilibrium with oxide

$D$ : diffusivity of deoxidizer element in metal.

Substituting $C_{o}-C_{s}=0.06 \%$ for $\mathrm{SiO}_{2}$ formation into Eq. (10),

$$
r \fallingdotseq 6.3 \times 10^{-4} t^{1 / 2}+7.5 \times 10^{-8}
$$

A plot of this relationship is also shown in Fig. 6 . 
At a later stage, growth is controlled by the diffusion mechanism.

(iii) Growth during Floatation

Miyashita ${ }^{8)}$ calculated the growth rate assuming that a particle during floatation absorbs small particles. Assuming that floatation of a particle obeys Stokes' law,

$$
v=\frac{2}{9} \frac{g r^{2}}{\eta}\left(\rho_{M}-\rho_{s}\right)=k r^{2}
$$

where, $v$ : floating velocity

$g$ : acceleration of gravity.

The volume passed by a particle in time $\Delta t$ is,

$$
\pi r^{2} v \Delta t
$$

the volume of small particles absorbed is,

$$
\pi r^{2} v \Delta t \cdot \alpha
$$

where $\alpha$ is the volume of small particles in unit volume of metal at time $t_{k}$. From the mass balance,

$$
\frac{4}{3} \pi(r+\Delta r)^{3}-\frac{4}{3} \pi r^{3}=\pi r^{2} v \Delta t \cdot \alpha
$$

Neglecting the terms with $(\Delta r)^{2}$ and higher,

$$
\frac{d r}{d t}=\frac{v \alpha}{4}=C r^{2}
$$

therefore, integrating Eq. (13) with the initial condition $r=r_{0} *$ at $t=0$,

$$
r=\frac{r_{0}^{*}}{1-C r_{0}^{*} t}
$$

For $\mathrm{SiO}_{2}$ formation,

$$
r=\frac{7.9 \times 10^{-7}}{1-3.3 \times 10^{-5} t}
$$

where $\alpha$ is referred to $t_{k}$.

As shown in Fig. 6, the radius increases suddenly at $t=3 \times 10^{-4} \mathrm{sec}$ and it is clear that this mechanism alone is insufficient to account for the observed behaviour.

(iv) Combination of Mechanisms (i), (ii), and (iii)

If coalescence during floatation and growth by diffusion occur simultaneously and independently, then:

$$
d r=\left(C r^{2}+a / r\right) d t
$$

Integrating Eq. (16),

$$
\begin{aligned}
& \left(a C^{2}\right)^{-1 / 3}\left\{\frac{1}{\sqrt{ } 3} \tan ^{-1} \frac{2(C / a)^{1 / 3} r-1}{\sqrt{3}}\right. \\
& \left.-\frac{1}{6} \ln \left[1+\frac{3(C / a)^{2 / 3} r^{2}+3(C / a)^{1 / 3} r}{1+(C / a) r^{3}}\right]+\frac{\pi}{6 \sqrt{ } 3}\right\}=t
\end{aligned}
$$

This equation is also included in Fig. 6 and the sudden increase in radius occurs at

$$
t=\left(a C^{2}\right)^{-1 / 3} \frac{2 \sqrt{3}}{9} \mathrm{sec}
$$

(v) The Size of Particles Observable, $r_{\mathrm{ob}}$

(1) Particles grow only by diffusion and rise up through the melt in accordance with Stokes' law.

Distance of floatation $h$ is

$$
h=\int v d t=\int k r^{2} d t \fallingdotseq a k t^{2}
$$

Therefore,

$$
t_{\mathrm{ob}} \fallingdotseq \sqrt{\frac{h}{a k}, \quad r_{\mathrm{ob}}=\sqrt{ } 2\left(\frac{h a}{k}\right)^{1 / 4}}
$$

From Eq. (19) $t_{\mathrm{ob}}=21 \mathrm{sec}, \quad r_{\mathrm{ob}}=27 \mu$ for $\mathrm{SiO}_{2}$

$$
t_{\mathrm{ob}}=33 \mathrm{sec}, \quad r_{\mathrm{ob}}=35 \mu \text { for } \mathrm{MnO}
$$

(2) Particles grow by diffusion and simultaneously coalesce during floatation.

Using Eq. (17) and the initial condition $r=r^{*}$ at $h=0$,

were calculated.

$$
\begin{array}{lll}
t_{\mathrm{ob}}=18 \mathrm{sec}, & r_{\mathrm{ob}}=6.2 \mu & \text { for } \mathrm{SiO}_{2} \\
t_{\mathrm{ob}}=32 \mathrm{sec}, & r_{\mathrm{ob}}=50 \mu & \text { for } \mathrm{MnO}
\end{array}
$$

These calculations mean that a particle which nucleates at the bottom of a crucible will grow, float, and be removed from the melt after a time $t_{\mathrm{ob}}$ and with a size $r_{\mathrm{ob}}$.

The experimental results are now discussed in the light of the above theoretical considerations.

For the formation of $\mathrm{SiO}_{2}$ inclusions, there is reasonable agreement between the particle size observed experimentally and that predicted by Eq. (19). This implies that silica particles do not coalesce during floatation, but rise through the melt in agreement with Stokes' law.

On the other hand, with manganese deoxidation, there is reasonable agreement between experiment and theory when coalescence is taken into consideration. On the basis of equilibrium diagram, it is suggested that when a metallic manganese particle dissolves in liquid iron, liquid $\mathrm{FeO}-\mathrm{MnO}$ particles may form some distance away from dissolving manganese and solid FeO-MnO particles may form near by. ${ }^{9)}$ It is possible that when particles coalesce, the liquid oxide phase behaves like a binder.

In complex silico-manganese deoxidation, a considerable amount of coalescence occurs during floatation even when the formation of a solid oxide product is expected. While manganese added after silicon does not reduce silica particles, silicon added after manganese does reduce the rim of solid $\mathrm{MnO}$ particles, forming a liquid and encouraging coalescence.

\section{Deoxidation of Stirred Melts}

An investigation has been made of the effect of bath motion, temperature, crucible materials, and the ratio of manganese and silicon added on the deoxidation kinetics.

\section{Deoxidation by Silicon}

Fig. 7 shows the variation in oxygen content with time using different crucibles. The higher the initial 


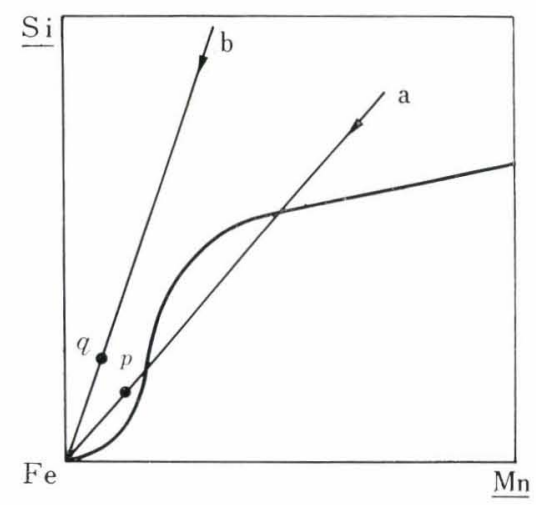

Fig. 7. Relation between manganese and silicon contents of silica-saturated slag

oxygen content, the greater the rate of deoxidation and the greater the rate of oxidation silicon. Initially the iron-oxygen melt was in equilibrium with ferrous oxide saturated with respect to the crucible material and the oxygen contents were $0.08,0.17,0.23$, and $0.09 \%$ for silica, alumina, magnesia, and lime crucibles, respectively. While the size of the deoxidation products was the same for stirred and unstirred melts, their number decreased more rapidly in the stirred melts.

The deoxidation rate increased with increasing silicon content up to $0.4 \%$ but beyond this amount no difference could be detected either in the rate or in the size of the deoxidation products. The amount of the silicon loss increased with the amount of silicon added, due to reaction with the ferrous oxide as well as the oxygen dissolved in the melt.

At higher temperature, no significant difference was observed in the deoxidation rate during the initial stages, but the rate of removal of silica improved after longer times.

\section{Deoxidation by Manganese}

The effect of crucible material on the rate of deoxidation with manganese was similar to that observed with silicon except that the oxygen concentration passed through a minimum and then increased again.

Manganese oxidation rates were small in magnesia and lime crucibles, where solid oxide products were formed. The products seemed to consist of two grey and black phases, which suggest that liquid and solid particles joined together to give particles of about $150 \mu$. Contrary to the behaviours observed with silicon, the effect of stirring was insignificant (Fig. 4).

In silica crucibles, as the amount of manganese added increased, the rate of removal of manganese and oxygen from the melt also increased. During an experiment, manganese evaporated continuously, and towards the end of a heat the amount of oxygen in the melt and the amount of silicon picked up from the crucible were controlled by the manganese content remaining. This was confirmed by placing a silica ring (20 mm i.d.) on the surface of the melt and reducing the gas/metal interfacial area by three quarters. It was found that the rate of manganese removal was reduced three quarters while the silicon and oxygen contents remained almost unchanged.

\section{Silico-Manganese Deoxidation}

With the addition of $0.8 \%$ manganese and $0.2 \%$ silicon, large spherical liquid silicates were formed which separated from the melt after a very short time. The rate of deoxidation was too rapid for any stirring effect to be detected.

A study was made of the effect of manganese/silicon ratio in the deoxidizer addition as follows:

i. $\quad 0.2 \%$ Silicon

As the amount of manganese added increased, the rate of deoxidation increased.

ii. $0.4 \%$ Silicon

No difference in the deoxidation rate was observed for manganese additions up to $1.2 \%$ due to the fact that solid, rather than liquid, deoxidation products were formed.

iii. $0.8 \%$ Silicon

No effect observed.

iv. $0.4 \%$ Silicon- $0.4 \%$ Manganese Alloy

The rate of deoxidation after this alloy addition was greater than when the silicon and manganese had simply been added in the form of a mixture. In this case the deoxidation product should be solid silica. With $0.2 \%$ silicon and $0.8 \%$ manganese, no difference was observed between the mixture and the alloy. This suggests that liquid silicates readily coalesce but solid silicates can have a range of compositions, dependent upon the method of addition.

\section{Growth Rate of a Deoxidation Product and the Effect of Stirring}

If, as mentioned in Section $\mathbf{I I I}$-1, the coalescence of particles during floatation is important, then stirring, by increasing the speed of floatation, should have an effect on particle growth.

Considering the growth of silica inclusion by diffusion alone and calculating the stream velocity $V_{0}$ in liquid iron by the method of Knüppel:10)

$$
\begin{aligned}
& V_{0}=\sqrt{ } 2 g H \\
& H=\frac{a \mathcal{N} i}{\sqrt{f} A}
\end{aligned}
$$

where, $H$ : rise up of melt surface by induction

$A$ : surface area of melt

$f$ : frequency of induction current

$\mathrm{Ni}$ : output of power

$a$ : constant.

Using the experimental conditions, $V_{0}$ and $t_{\mathrm{ob}}$ were calculated to be $70 \mathrm{~cm} / \mathrm{sec}$ and $0.10 \mathrm{sec}$, respectively. Therefore, from Eqs. (18) and (19) the maximum size of silica inclusions was found to be $2 \mu$. This treatment assumes that particles float up vertically through the melt with the stream. A comparison of the calculated result with that observed experimentally suggests that this assumption is unjustified and that in fact a particle follows an irregular path up through the melt to the surface and then comes back down into the melt again, thus providing a longer time for particle growth.

In the case of $\mathrm{MnO}$ inclusions, the effect of coalescence during floatation was taken into account. The 
maximum particle size, calculated from the following equations, is $29 \mu$ and this is in reasonable agreement with the experimented observations. by

Similar to Eq. (16) growth of a particle is expressed

$$
d r=\alpha V_{0} d t+\frac{a}{r} d t
$$

Integrating Eq. (22) and using the relation $h=V_{0} t$,

$$
r_{\mathrm{ob}} \fallingdotseq h \alpha=29 \mu \text { for } \mathrm{MnO}
$$

where $h$ is a depth of melt $(7.0 \mathrm{~cm})$.

Thus the particle size observed in both stirred and unstirred melts was of the same order, but the time required for growth was much shorter with the stirred melts.

\section{Type of Deoxidation Product}

i. Silicon Deoxidation

For silicon concentrations more than $0.003 \%$, the deoxidation product in equilibrium with an ironsilicon-oxygen melt is pure silica, and since the rate of nucleation at such small concentrations is very slow, there should be no $\mathrm{FeO}-\mathrm{SiO}_{2}$ inclusion formed.

ii. Silico-Manganese Deoxidation

According to Körber and Oelsen, ${ }^{9)}$ if the $\mathrm{Si}: \mathrm{Mn}$ ratio lies on line "a " in Fig. 7, liquid silicates may be formed when the deoxidizers dissolve in the melt even though the final product should be solid silica. This would be most pronounced, when the deoxidizer is added in the form of an alloy.

\section{Reaction Kinetics}

Since the reaction at the interface between the melt and the oxide formed initially was found to be just as important as the bulk reaction, the kinetics of the interfacial reaction will be discussed in the following section.

i. Silicon Deoxidation

(a) Bulk Reaction

$\underline{\mathrm{Si}}+2 \underline{\mathrm{O}}=\mathrm{SiO}_{2}$ Particle floats out of melt into the slag.

(b) Metal-Slag Reaction

$$
\begin{aligned}
& \left.\begin{array}{l}
\mathrm{Si} \rightarrow \mathrm{Si}^{4+}+4 e \\
\mathrm{O}^{2-} \rightarrow \underline{\mathrm{O}}+2 e
\end{array}\right\} \text { anodic reaction } \\
& \mathrm{Fe}^{2+}+2 e \rightarrow \mathrm{Fe} \text { cathodic reaction }
\end{aligned}
$$

The rate of metal-slag reaction depends on the activity of silica in the slag phase as well as the physical properties of the slag and thus a difference in the rate of change of the silicon and oxygen contents of liquid iron is to be expected, with the different crucible materials.

While the anodic reaction involving silicon is negligible in silica crucibles (activity of $\mathrm{SiO}_{2}$ is unity), it proceeds very rapidly in magnesia and lime crucibles, where the activity of silica in the slag phase is low, the initial FeO content is high, and the slag is very fluid. The high FeO content of the slag favours the recovery of oxygen at a later stage.

Since the $K_{\text {Si }}^{\prime}$ values increased after reaching a minimum, the reaction:

$$
\mathrm{Fe}^{2+}+2 e \rightarrow \mathrm{Fe}, \quad \mathrm{O}^{2-} \rightarrow \underline{\mathrm{O}}+2 e
$$

are considered to occur independently of the reaction:

$$
\underline{\mathrm{Si}} \rightarrow \mathrm{Si}^{4+}+4 e
$$

where King ${ }^{11)}$ suggests the rate determining step is the formation of a complicated silicate ion.

ii. Manganese Deoxidation

Initial Stage:

(a) Bulk Reaction:

$\underline{\mathrm{Mn}}+\underline{\mathrm{O}} \rightarrow \mathrm{MnO}$ Particle floats out of melt into slag.

(b) Metal-Slag Reaction:

$$
\left.\begin{array}{l}
\left.\begin{array}{l}
\mathrm{Mn} \rightarrow \mathrm{Mn}^{2+}+2 e \\
\mathrm{O}^{2-} \rightarrow \underline{\mathrm{O}}+2 e
\end{array}\right\} \text { anodic reaction } \\
\mathrm{Fe}^{2+}+2 e \rightarrow \mathrm{Fe} \\
\left(\mathrm{Si}^{4+}+4 e \rightarrow \mathrm{Si}\right. \text { when } \\
\text { silica crucible is used. })
\end{array}\right\} \text { cathodic reaction }
$$

Later Stage:

$$
\left.\begin{array}{l}
\mathrm{O}^{2-} \rightarrow \underline{\mathrm{O}}+2 e \text { anodic reaction } \\
\mathrm{Mn}^{2+}+2 e \rightarrow \underline{\mathrm{Mn}} \\
\mathrm{Fe}^{2+}+2 e \rightarrow \mathrm{Fe}
\end{array}\right\} \text { cathodic reaction }
$$

Initially the reactions are similar to those for the addition of silicon. The typical behaviour observed in the later stage is controlled by manganese evaporation. Manganese is transferred to the slag initially but subsequently returns to the metal and this is accompanied by an increase in $\mathrm{O}$ and $\mathrm{Fe}^{2+}$.

Ward $^{12}$ found that the rate determining step of manganese evaporation was the diffusion of manganese vapour through the boundary layer.

In the present work, higher rates were observed and this suggests that the rate determining step was the diffusion of manganese from the bulk of the metal bath to the surface.

By Fick's law:

$$
\frac{d(\% \mathrm{Mn})}{d t}=-\frac{k A}{V}(\% \mathrm{Mn})
$$

where, $k: D_{\mathrm{Mn}}$

$\delta$ : thickness of boundary layer.

Substituting the numerical values, $\frac{A}{V}=7.0 \mathrm{~cm}$ and $\frac{D_{\mathrm{Mn}}}{\delta}=0.03 \mathrm{~cm} / \mathrm{sec}$, the half life was calculated to be $6.3 \mathrm{~min}$ which agrees reasonably well with the experimental values, $6.6 \mathrm{~min}(0.4 \% \mathrm{Mn}$ added $), 6.2 \mathrm{~min}$ $(0.8 \% \mathrm{Mn}$ added $)$. When $1.5 \% \mathrm{Mn}$ added, the agreement with the experimental value of $8.0 \mathrm{~min}$ is not so good, probably because gaseous diffusion becomes more important.

\section{Deoxidation Accompanied by Reoxidation with Air}

A series of experiments was made in which deoxidation was accompanied by reoxidation with oxygen supplied from outside the system, thus simulating the conditions which exist in practical steelmaking.

\section{Deoxidation by Silicon}

Using magnesia crucibles, the oxygen content decreased from $0.22 \%$ at $1600^{\circ} \mathrm{C}$, with the addition of silicon, reached a minimum, and then increased again to the original value due to reoxidation by air. This effect is shown in Fig. 8, for the addition of $0.4 \%$ silicon. The minimum point in the air $(0.10 \%)$ was slightly greater than that found with argon $(0.08 \%)$. 
As the amount of silicon added was increased, the minimum attained decreased, and the time required to reach this minimum increased. The rate of reoxidation was also slower.

During the first $3 \mathrm{~min}$ after the addition of deoxidizer, the deoxidation products consisted of glassy silica. After $3 \mathrm{~min}$, fayalite and wustite were observed but it is considered that they were formed during solidification.

\section{Deoxidation by Manganese}

The results obtained with the addition of $1.0 \%$ manganese are shown in Fig. 9. When the actual oxygen content of the melt $\underline{\mathrm{O}}$, and the equilibrium oxygen content $\underline{\mathrm{O}}_{\mathrm{eq}}$ for a particular manganese content are plotted together, the two concentrations are almost the same at the minimum. Then during reoxidation, in contrast to the behaviour observed with silicon, the actual oxygen content was less than the

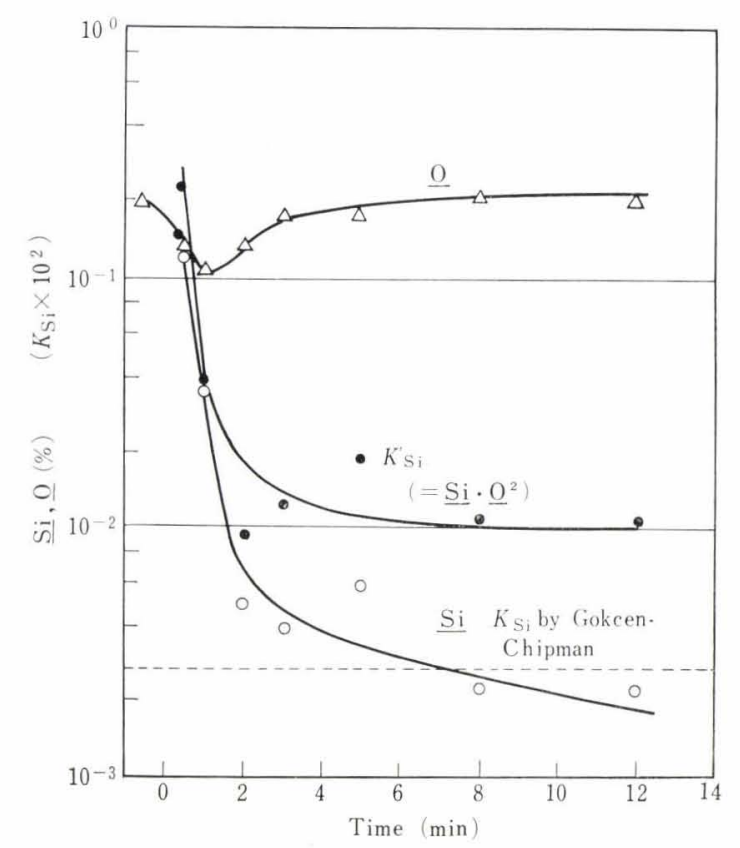

Fig. 8. Run of deoxidation after the addition of $0.4 \%$ silicon at $1600^{\circ} \mathrm{C}$ when the oxidation accompanied

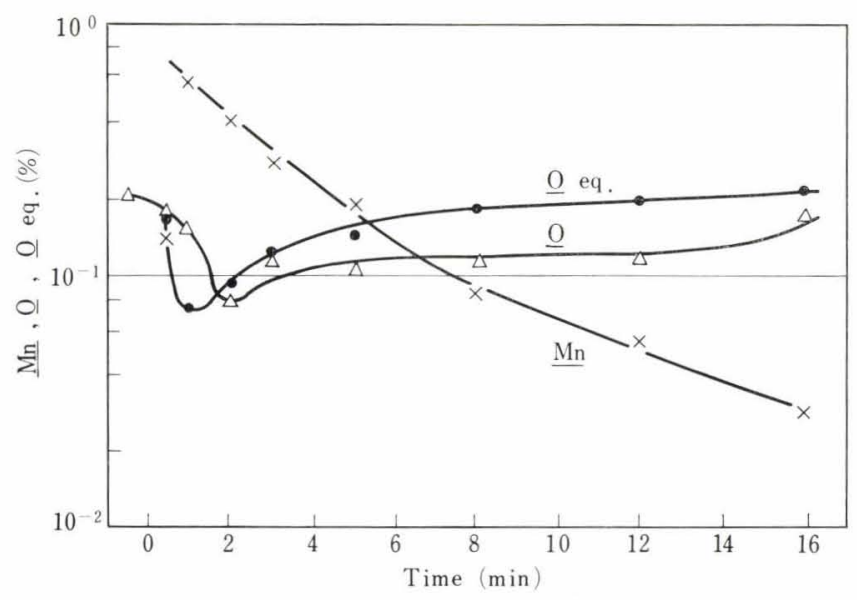

Fig. 9. Run of deoxidation after the addition of $1.0 \%$ manganese at $1600^{\circ} \mathrm{C}$. O eq. is the equilibrium oxygen content with $\mathrm{Mn}$ equilibrium content due to loss of manganese evaporation.

When the manganese content of the melt is plotted against time on a semilogarithmic scale, two straight lines are apparently obtained, the slopes of which are listed in Table 2.

Table 2. Rate of manganese elimination by various amount of addition

\begin{tabular}{l|cc}
\hline & $\begin{array}{c}\text { Slope of the first } \\
\text { line }(l / \mathrm{min})\end{array}$ & $\begin{array}{c}\text { Slope of the second } \\
\text { line }(l / \mathrm{min})\end{array}$ \\
\hline $0.8 \% \mathrm{Mn}$ added & 0.13 & 0.030 \\
$1.2 \%, "$, & 0.15 & 0.064 \\
$2.0 \%, "$, & 0.20 & 0.054
\end{tabular}

\section{Reaction Mechanism}

While deoxidation reactions reduce the oxygen content of the melt, there is a simultaneous pick-up of oxygen from the air due to the difference of oxygen potential between the slag and the air, caused by deoxidation.

The following reactions occur at the slag/air interface:

$$
\begin{aligned}
& \frac{1}{2} \mathrm{O}_{2}+2 e \rightarrow \mathrm{O}^{2-} \quad \text { cathodic reaction } \\
& 2 \mathrm{Fe}^{2+} \rightarrow 2 \mathrm{Fe}^{3+}+2 e \text { anodic reaction }
\end{aligned}
$$

$\mathrm{Fe}^{3+}$ and $\mathrm{O}^{2-}$ ions diffuse to the slag-metal interface where the following reactions take place:

$2 \mathrm{Fe}^{3+}+2 e \rightarrow 2 \mathrm{Fe}^{2+} \quad$ cathodic reaction

$$
\left.\begin{array}{l}
\mathrm{O}^{2-} \rightarrow \underline{\mathrm{O}}+2 e\left(\frac{1}{2} \mathrm{Si} \rightarrow \frac{1}{2} \mathrm{Si}^{4+}+2 e\right) \\
\mathrm{Fe} \rightarrow \mathrm{Fe}^{2+}+2 e\left(\underline{\mathrm{Mn}} \rightarrow \mathrm{Mn}^{2+}+2 e\right)
\end{array}\right\} \text { anodic reaction }
$$

The experimental results for each of these reactions were interpreted electrochemically (Fig. 10).

During the later stages after the addition of manganese, the equilibrium potential $E_{\mathrm{Mn}^{2+} / \mathrm{Mn}}$ is greater than $E_{\mathrm{O} / \mathrm{O}^{2-}}$ and $i_{\mathrm{O}}$ is smaller than $i_{\mathrm{Fe}}$ at the mixed

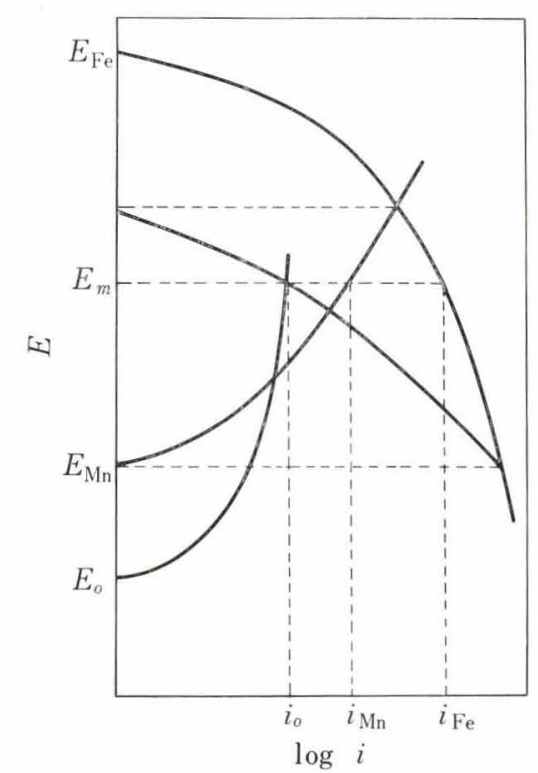

Fig. 10. Polarization curves for the explanation of manganese-deoxidation 
potential $E_{m}$, which means that the rate of oxygen pick-up is less than the rate of manganese loss so that $\underline{\mathrm{O}}_{\mathrm{eq}}>\underline{\mathrm{O}}$.

Finally $\underline{\mathrm{O}}$ attains the saturation level again and $E_{\mathrm{Mn}^{2+} / \mathrm{Mn}}=E_{\mathrm{O} / \mathrm{O}^{2-}}=E_{\mathrm{Fe}^{2+} / \mathrm{Fe}}$. If $E_{\mathrm{Mn}^{2+} / \mathrm{Mn}}$ is less than that shown in Fig. 10, i.e. more manganese is added initial$\mathrm{ly}, i_{\mathrm{O}}$ is smaller and $i_{\mathrm{Mn}}$ increases. If the polarization curve for oxygen shows the diffusion-limited current, $i_{\mathrm{Mn}}$ and $i_{\mathrm{O}}$ will be independent of the amount of manganese added. Unfortunately polarization curves of these reactions are not available at the present time and a quantitative analysis cannot be made.

For the behaviour observed with silicon, $i_{\mathrm{O}}>i_{\mathrm{Si}}$, and this is shown in Fig. 11.

\section{Reaction Rate Calculations}

i. Silicon and Manganese

The reactions in the bulk phase to form a separate oxide phase (a) and the interfacial reaction between slag and metal (b) were assumed to take place independently.

The rate of (a) is:

$$
\frac{d C}{d t}=-k_{1}\left(C-C_{0}\right)=k_{1}\left(C_{0}-C_{1}\right) e^{-k_{1} t}
$$

where, $C_{0}$ : equilibrium concentration

$$
C_{1} \text { : initial concentration. }
$$

The rate of (b) is:

$$
\frac{d C}{d t}=-k_{2} C
$$

combining Eqs. (25) and (26),

$$
\frac{d C}{d t}=k_{1}\left(C_{0}-C_{2}\right) e^{-k_{1} t}-k_{2} C
$$

integrating Eq. (27),

$$
C=\frac{C_{0} k_{1}-C_{1} k_{2}}{k_{1}-k_{2}} e^{-k_{2} t}+\frac{k_{1}\left(C_{1}-C_{0}\right)}{k_{1}-k_{2}} e^{-k_{1} t}
$$

From this equation, when $t \rightarrow \infty, C \rightarrow 0$, and when $k_{1} \gg k_{2}$ and $t \gg 0$, the first term remains and a semilogarithmic plot will yield a straight line, the slope of which is $k_{2}$.

Noting the difference in experimental conditions
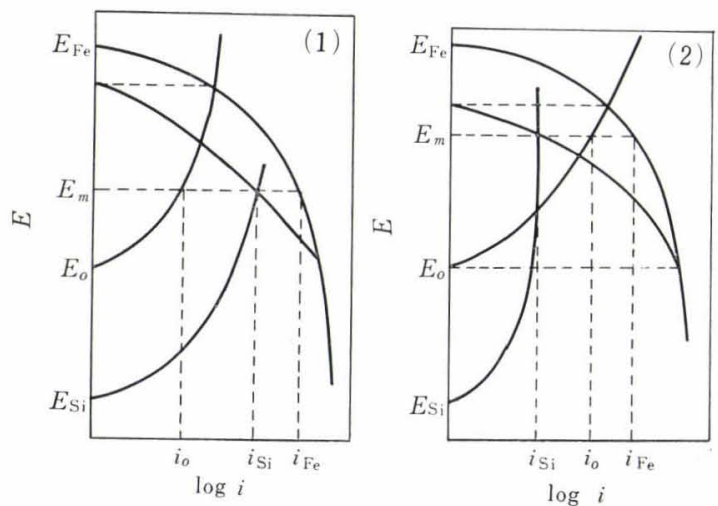

Fig. 11. Polarization curves for the explanation of silicondeoxidation between Sections $\boldsymbol{I I I}-2$ and 3, the manganese evaporation rate under the oxidizing atmosphere was calculated from the rate obtained under the neutral atmosphere.

Combining the non-dimensional equations for heat convection $^{13)}$ with that for the motion of an induction stirred bath,

$$
k \propto D^{0.7} \nu^{-0.5} \mathcal{N}^{0.4} f^{-0.2} r^{3} V^{-1}
$$

$$
\begin{aligned}
\text { where, } & k: \text { mass transfer coefficient } \\
D & : \text { diffusivity } \\
\nu: & \text { kinematic viscosity } \\
\mathcal{N}: & \text { power output of induction current } \\
f: & \text { frequency } \\
r: & \text { radius of crucible. }
\end{aligned}
$$

Using this equation, a value of $0.05 \% / \mathrm{min}$ was calculated for $k$ which is in good agreement with the experimental data shown in Table 2.

ii. Oxygen

Assuming that a similar situation exists for oxygen and for silicon, then for the bulk reaction:

$$
\frac{d C}{d t}=-k_{1} C=-k_{1} C_{0} e^{-k_{1} t}
$$

For the interfacial reaction,

$$
\frac{d C}{d t}=k_{2}\left(C_{1}-C\right)
$$

Combining Eqs. (30) and (31) and integrating, when $k_{1} \neq k_{2}$,

$$
\begin{gathered}
C=C_{1}-\frac{\left\{\left(C_{0}-C_{1}\right) k_{2}+C_{1} k_{1}\right\}}{k_{1}-k_{2}} e^{-k_{2} t}+\frac{C_{0} k_{1}}{k_{1}-k_{2}} e^{-k_{1} t} \\
t_{\min }=\left(\ln \frac{x^{2}}{1-y+x y}\right) / k(x-1) \ldots \ldots . \\
\frac{C_{\min }}{C_{0}}=y-\left[\frac{x^{1+x}}{(1-y+x y)^{x}}\right]^{1 /(1-x)} \ldots \ldots
\end{gathered}
$$

when $k_{1}=k_{2}$,

$$
\begin{aligned}
& C=C_{1}+\left(C_{0}-C_{1}\right) e^{-k_{1} t}-C_{0} k_{1} t e^{-k_{1} t} \\
& t_{\min }=\frac{2-y}{k_{1}} \\
& \frac{C_{\min }}{C_{0}}=y-e^{y-2} \\
& y=C_{1} / C_{0} \text {. }
\end{aligned}
$$$$
\text { where, } \quad x=k_{1} / k_{2}
$$

The relationship between $C$ and $t$ is shown in Fig. 12 for $k=0.50 / \mathrm{min}, k_{2}=0.25 / \mathrm{min}$, and $C_{0}=C_{1}$, and the oxygen content $c$ returns to its original value after passing through a minimum.

Figs. 13 and 14 show the relationship between $k_{1} / k_{2}$ and $C_{\min } / C_{0}$ and between $C_{\min } / C_{0}$ and $x, y$, respectively when $C_{0}=C_{1}$.

Finally a comparison was made between the experimental results of this investigation and the results obtained from deoxidation in a 150-t basic open hearth furnace. Melts were deoxidized with ferrosilicon, 


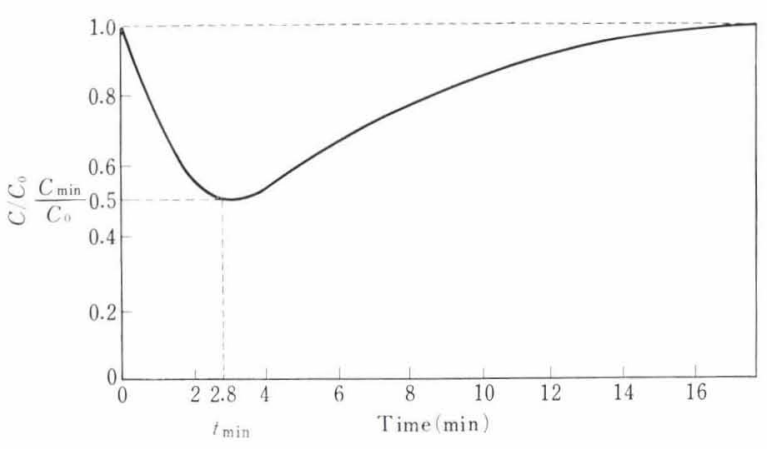

Fig. 12. Calculated behaviour of oxygen contents

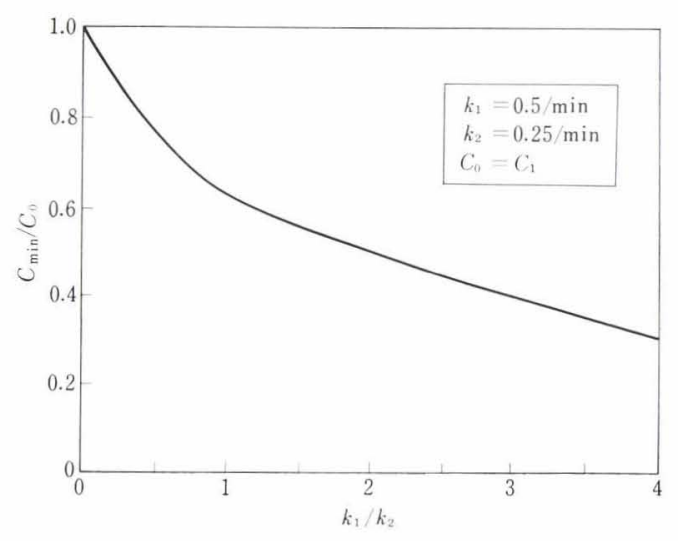

Fig. 13. Minimum oxygen content vs. $k_{1} / k_{2}$ value

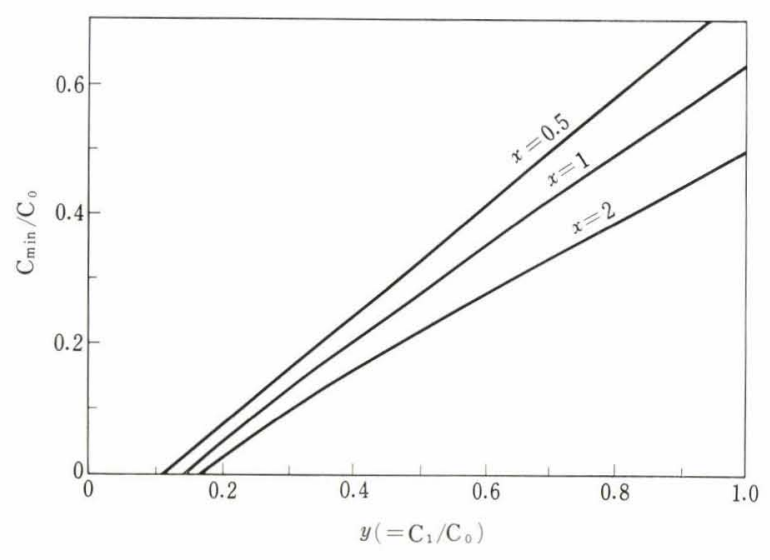

Fig. 14. Calculated minimum oxygen content related at $C_{1} / C_{0}, k_{1} / k_{2}$ values

ferromanganese, and silico-manganese. When Si-Mn (20: 70) was added $(0.50 \% \mathrm{Mn}, 0.10 \% \mathrm{Si})$, the greatest rate of deoxidation was observed and this was followed by a subsequent reoxidation. The $\mathrm{FeO}$ content in the slag decreased after the initial $\underline{O}$ drop. This implies that the bulk reaction is predominant during the first stage. On the other hand when Fe-Mn was added both the slag-metal reaction and the bulk reaction took place together, and the FeO content of the slag decreased immediately after the addition of deoxidizers.

In Si-Mn deoxidation, $k_{1} / k_{2}$ is larger and $C_{\min }$ and $t_{\text {min }}$ were smaller than for deoxidation with ferromanganese (Eq. (34)).

\section{Conclusion}

In an unstirred bath, silica inclusions were too small to separate easily from the melt. With manganese deoxidation, larger two-phase particles were observed and deoxidation proceeded at a faster rate. The results of calculations on nucleation rate and growth mechanisms are in good agreement with the experimental data.

In a stirred bath, the size of the deoxidation products remained the same but their rate of removal was increased. With manganese present, the evaporation of this element controlled the behaviour of the other solutes, particularly in the later stages of the process. In general, larger $\mathrm{Mn}$ : Si ratio favoured the formation of liquid silicates even in cases where silica would have been expected to form, and these silicates separated very quickly from the melt.

When deoxidation reactions were studied in the presence of air, reoxidation occurred in a very short time. In the silicon deoxidation, reoxidation was not so rapid, due to the formation of thick oxide film on the surface of the melt.

\section{Acknowledgement}

The authors wish to thank Dr. A. McLean, McMaster University, Hamilton, Ontario, Canada, for helpful suggestions in preparing this manuscript.

\section{REFERENCES}

1) R. A. Walsch and S. Ramachandran: Trans. Met. Soc., Amer. Inst. Min., Met. \& Pet. Eng., 227 (1963), 560.

2) L. von Bogdandy and W. Meyer: Arch. Eisenhüttenw., 32 (1961), 451.

3) Progress in Metal Physics, 4 (1953), 343, Pergamon Press, New York.

4) С. И. Поперь: Из ВУЗ (Уерная Металлургия), 4 (1962), 5.

5) L. von Bogdandy: Arch. Eisenhüttenw., 32 (1961), 287.

6) T. Katsurai: Koroido no Riron, (1947), 68, Kawade Shobo, Tokyo.

7) R. B. Bird, W. E. Stewart, and E. N. Lightfood: Transport Phenomena, (1960), 527, John Wiley \& Sons, NewYork.

8) Y. Miyashita: Gakushin (Japan Society for the Promotion of Science) No. 7516, (1964), (in Japanese).

9) F. Körber and W. Oelsen: Mitt. $K$-W. Inst. Eisenforschung, 15 (1933), 271.

10) H. Knüppel and F. Oeters: Arch. Eisenhüttenwe, 33 (1962), 729.

11) C. E. Sims: Electric Furnace Steelmaking, II (1963), Met. Soc., Amer. Inst. Min., Met. \& Pet. Eng.

12) R. G. Ward: J. Iron Steel Inst. (U.K.), (1963), Part I, 11.

13) E. R. G. Eckert: Heat and Mass Transfer, (1959), 211, McGraw-Hill, New York. 